\title{
Preliminary ASTER and InSAR Imagery Combination for Mud Volcano Dynamics, Azerbaijan
}

\author{
K.H.Scholte ${ }^{\mathrm{a}}$, A.Hommels ${ }^{\mathrm{a}}$, F.D. Van der Meer $^{\mathrm{a}}$, S.B. Kroonenberg ${ }^{\mathrm{a}}$, R.F.Hanssen ${ }^{\mathrm{b}}$, E. Aliyeva ${ }^{\mathrm{c}}$, \\ D. Huseynov ${ }^{\mathrm{c}}$, I.Guliev ${ }^{\mathrm{c}}$ \\ ${ }^{a}$ Department of Applied Earth Sciences, Faculty of Civil Engineering and Geosciences, Delft \\ University of Technology, Mijnbouwstraat 120, 2628 RX Delft, The Netherlands \\ k.h.scholte@,citg.tudelft.nl \\ ${ }^{b}$ Department of Geodetic Engineering, Delft University of Technology, The Netherlands \\ ${ }^{c}$ Geological Institute of the National Academy of Sciences of Azerbaijan, Azerbaijan
}

\begin{abstract}
In Azerbaijan oil mud volcanoes form on the surface as expressions of the vertical migration of oil and gas as a result of gravitational loading of largely unconsolidated sediments in combination with structure control and stress regime. In general it is believed that mud volcano eruptions are triggered by earthquake activity since this can cause hydrate instability and explosive dissociation of the hydrocarbons can occur. Through typical geomorphologic mud volcano vents called gryphons and salses, mud volcanoes eject argillaceous material (breccia) and build up their topography. Optical satellite images (Advanced Spaceborne Thermal Emission and Reflection - ASTER) and ground truth data from 2000 to 2002, centred on onshore Azerbaijan, are analysed using Variable Multiple Endmember Spectral Mixture Analysis (VMESMA) in combination with Interferometric Synthetic Aperture Radar (InSAR) from six ERS2 scenes from 1996 to 1999. ASTER and InSAR imagery are used to look for evidence of mineral alterations and precursory surface deformation related to mud volcanism. Preliminary field spectral data of 5 onshore mud volcano vents show typical mineral zonations present in the mud breccia fields. ASTER image analyses on Aktharma-Pashaly mud volcano shows Al-OH mineral zonation patterns over various mud volcano vents. Initial InSAR processing for Aktharma Pashaly shows little correlation over this particular mud volcano, which makes it hard to assess data combinations of ASTER and InSAR. Fair correlation was found for Touragai, Great - and Lesser Kjanizadag mud volcanoes showing high to moderate correlation over a time period of 3 years.
\end{abstract}

Keywords: Mud volcano, ASTER, Hyperspectral, Spectral Mixture Analysis, InSAR, Mineralogy, Azerbaijan.

\section{INTRODUCTION}

Azerbaijan, South Caspian Basin, is one of the oldest oil producing country in the world. Large oil and gas reserves have been proven for the country, most of which are at great depths in between 6 and $13 \mathrm{~km}$, and confined to Miocene and Pliocene palaeo Kura and palaeo Volga deltaic sediments in the onshore part [1] and [2]. The South Caspian Basin is characterized by very high basin sedimentation rates leading to large volumes of largely unconsolidated sediments of more than $20 \mathrm{~km}$ [1], [2], and [3]. The reason why mud volcanoes are present in such environments is discussed in [4] and [5] and they suggest that abnormally-high pore pressures may lead to lateral rock density variations, which in turn develop mud volcanism and earthquakes. Hydrates like methane exist under particular pressure-temperature conditions, and the impact of earthquakes or moving mudflows causes changing pressure-temperature conditions and hydrates may be dissociated and released as gas and water [3], [6]. Hence massive explosions and mud volcano eruptions can take place, such as the Lokbatan oil mud volcano on October 25,2001 . During this eruption hydrocarbons from earth's interior were set on fire resulting in a flame of about 50$60 \mathrm{~m}$ high and about $192,200 \mathrm{~m}^{3}$ mud was expelled covering an area of about 9.61 ha. Oil mud volcanoes thus form on the surface as expressions of the vertical migration of oil, gas, water, clays, and bedrock, and reflect the geologic history at a particular location [1], [2], and [3]. Different oil fields in Azerbaijan seem to have originated from common clastic, dark shale Source Rock (SR) with a restricted stratigraphic distribution, deposited in a transitional marine environment, referred to as the Maykop Suite [2], [7]. Productive Series (PS), sedimentary sequences from which the hydrocarbons can be produced, have significant mineral rock fragments [1] and [4]. The Great and Lesser Caucasus contain substantial Mesozoic and Cenozoic volcanigenic rocks that act as sources of montmorillonite-rich sediments [1]. Late Pliocene PS contains less quartz, more feldspar and fragments of both sedimentary and volcanic

Presented at the $3^{\text {rd }}$ EARSeL Workshop on Imaging Spectroscopy, Herrsching, 13-16 May 2003 
rock fragments, reflecting a more typical palaeo-Kura provenance. In general 'harder' minerals such as chlorite, illite, and kaolinite characterize Azerbaijan hydrocarbon reservoirs of argillaceous material [1]. In this paper we focus whether mud volcanic argillaceous materials can be assessed from field and imaging spectrometry, in combination with precursory surface deformation patterns extracted from Synthetic Aperture Radar imagery (InSAR) to monitor mud volcanism.

\section{MINERAL CONTENT OF MUD VOLCANO FLOW MIXTURES}

Basically we are interested in the mineral content of mud volcano flows since these reflect the initial products, the deep burial of rocks, and the particular assemblage of primary or secondary minerals of the subsurface. To assess possible surface alteration phenomena we look at the spectral reflectance properties of a various amount of clay minerals with typical assemblages for oil mud volcanoes being montmorillonite, chlorite, illite, and kaolinite. According to [8] and [9] long-term hydrocarbon leakage can establish locally anomalous redox zones that favour the development of a diverse array of chemical and mineralogical changes. At surface bleached and discoloured red sandstones above petroleum accumulation has been widely noted. Bleaching occurs whenever acidic, reducing fluids dissolve the ferric oxide (hematite) that gives the red bed its characteristic colour, which is observed at Ceildag and AktharmaPashaly mud volcanoes. The acidic conditions resulting from the oxidation of hydrocarbons in near-surface soils and sediments promote the diagenetic weathering of feldspar to clay and the conversion of smectite clay to kaolinite. The kaolinite formed remains chemically stable unless the environment is changed. Ferrous carbonate, also called "Delta C", show highs above the edges of hydrocarbon accumulations. The bicarbonate and carbonate chemistry of calcium and iron may provide a viable explanation for edge-leakage of Delta $\mathrm{C}$ iron carbonate anomalies.

Water and hydroxyl groups are present in clay-like group of minerals, but physical and chemical absorbed at specific locations on the crystal surface, which influences the spectral response [10]. Hydroxyl absorption is a result of the first overtone of $\mathrm{OH}$-stretching or due to combination bands of the fundamental stretch with $\mathrm{AlOH}$ or $\mathrm{Mg}$ $\mathrm{OH}$. Combination bands in the $2.0-2.5 \mu \mathrm{m}$ region that involve the $\mathrm{OH}$ fundamental stretching mode generally appear in pairs, with the shorter wavelength member typically near either 2.2 or $2.3 \mu \mathrm{m}$, and the accompanying feature near either 2.3 or $2.4 \mu \mathrm{m}$. The location of the more intense feature ap pears to depend upon whether aluminium is present, in which case it occurs near $2.2 \mu \mathrm{m}$, or whether magnesium is present, in which case it appears at $2.3 \mu \mathrm{m}$. Carbonate spectra features in the VNIR-SWIR electromagnetic window occur between 1.6 and $2.5 \mu \mathrm{m}$ as a result of overtone and combinations of the internal vibration of the carbonate ion. Carbonates are not usually associated with water so intense water features are frequently not present to confuse the spectra. Absorption features exhibit near 1.90, 2.00, 2.16, and $2.35 \mu \mathrm{m}$.

The ASTER SWIR reflective bands promise enhanced discrimination of mineral assemblages relative to Landsat TM and SPOT satellite data (table 1). For example, muscovite is characterised by a diagnostic absorption feature near $2.20 \mu \mathrm{m}$. When resampled to ASTER bandpasses the gross shape of the curve is preserved and the diagnostic features are depicted by a significant spectral absorption in band 6, centred at $2.205 \mu$ m. However ASTER probably cannot identify this mineral directly, but Al-OH bearing minerals (muscovitemontmorilloniteillite-Al smectite) could be identified as a group (figure 1). For the mapping of kaolinite using ASTER, the diagnostic doublet absorption feature near 2.175/2.210 $\mu \mathrm{m}$ shall disappear in the ASTER spectral curve, but the gross shape of the doublet will be preserved in terms of asymmetric absorption in band 6 (figure 1). Calcite and chlorite exhibit major absorption near aster band 8, centred at $2.32 \mu \mathrm{m}$ and hence ASTER bandpasses will show this feature in terms of symmetric absorption in band 8. Other common $\mathrm{MgOH}$ bearing minerals, which are characterised by absorption features ranging from 2.32 to $2.39 \mu \mathrm{m}$ have similar ASTER band 8 responses. ASTER will probably have troubles in separating carbonates from $\mathrm{MgOH}$ bearing minerals, however ASTER should be able to map these as a group (figure 1).

\section{DATA SET}

During extensive field campaigns in 2001 and 2002, representative mud volcano vents (Aktharma Pashaly, Lokbatan, Baghar, Bozdag Kobi, Ceildag, and Dashgil), Kirmaki outcrop (Productive Series), and Makhachkala (Dagestan: Source Rock) were selected. The fieldwork recognized yellowish clay of Miocene age (Maykop), and probable Pliocene sandstones and clays at Aktharma-Pashaly mud volcano. Spectral measurements using a FieldSpec FR, resulted in a VIS to SWIR high-resolution library of source rocks, productive series, mudflows, clasts, and vegetation, representing the spectral variability in the area. ASTER data from Aktharma-Pashaly (May 2001, March 2002, and July 2002), Lokbatan and Bozdag (March 2001, August 2002), Ceildag (March 2002) were acquired. For this study only Aktharma-Pashaly data were taking into consideration. 


\subsection{ASTER SWIR Calibration}

The ASTER scenes selected are of the L2 type and were obtained from the EROS Data Center (EDC). Prior to any image analysis an empirical line correction was carried out to correct for the 'crosstalk' instrument problem. This problem is caused by the reflectance of light from ASTER band 4 (centred at $1.65 \mu \mathrm{m}$ ) optical components; in particular ASTER band 5 (centred at $2.165 \mu \mathrm{m}$ ) and ASTER band 9 (centred at $2.39 \mu \mathrm{m}$ ) (Abrams, 2003, personal communication). Hence the sensor acquires inaccurate reflections and interpretation in terms of band absorption features is not feasible. Three ASTER images from Aktharma-Pashaly mud volcano were empirical line corrected using ground truth field spectral reflectance measurements.

Table 1. Possible mineral assemblages that can be detected by ASTER SWIR bandpasses

\begin{tabular}{cc}
\hline Absorption wavelength (um) & Mineral Group \\
\hline 2.165 & Low $\mathrm{pH} /$ acid environments \\
2.205 & Al-OH bearing minerals \\
2.260 & Jarosite \\
2.327 & Carbonates and Mg-OH bearing minerals \\
\hline
\end{tabular}

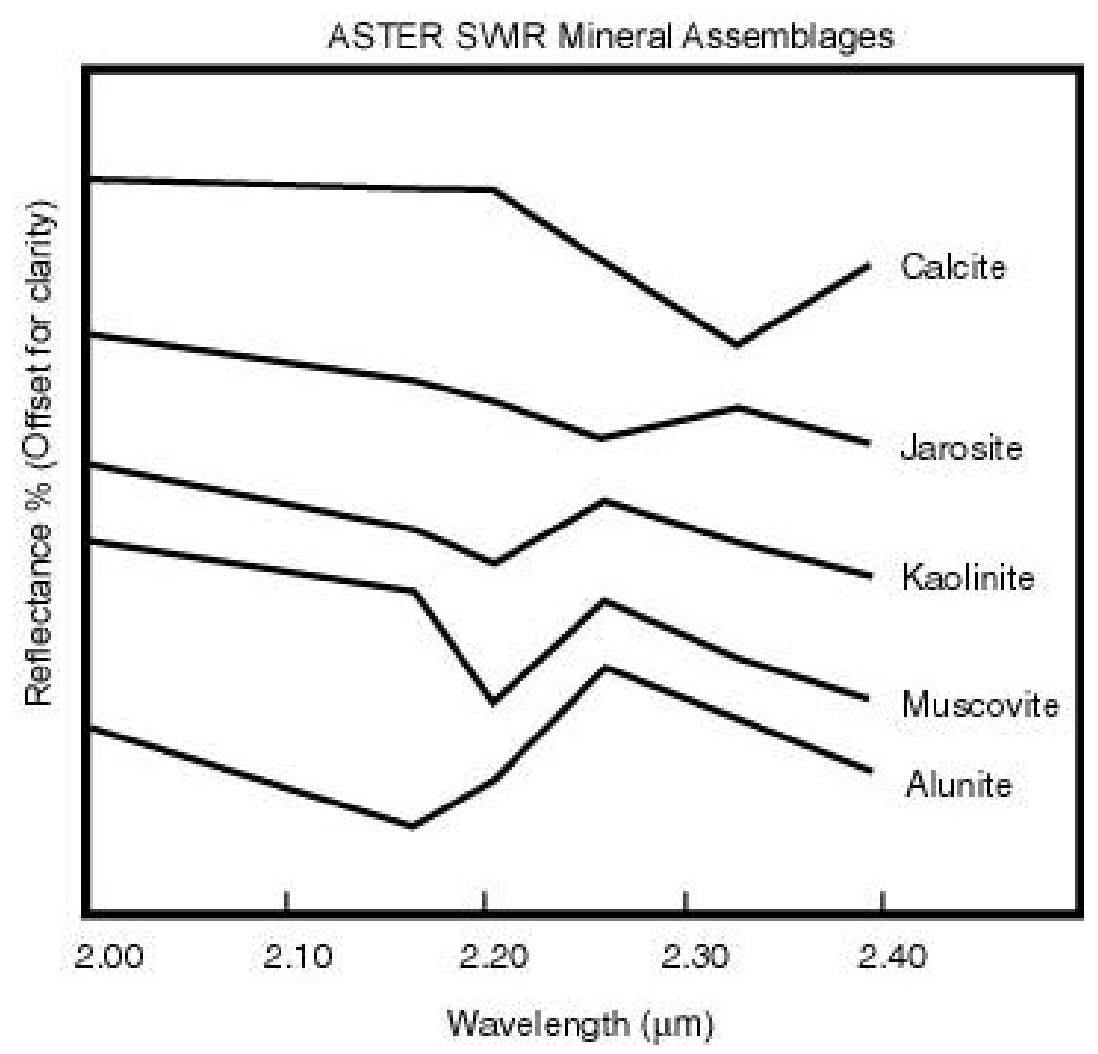

Figure 1. USGS mineral spectra resampled to ASTER bandpasses in order to show the gross shape curves of typical minerals that can be identified as a group. 


\section{METHODS}

We try to extract mineral provenance information from mud volcano flow mixtures through imaging spectroscopy in the $0.5-2.5 \mu \mathrm{m}$ part of the electromagnetic spectrum using Variable Multiple Endmember Spectral Mixture Analysis [12]. Spectral unmixing techniques strive at finding partial least squares solutions to the linear mixing of spectral components in order to derive fractional abundance estimates of selected endmembers. The VMESMA technique allows variable endmember sets for different parts of an image and uses a standardization of the data prior to unmixing. We use hyperspectral field measurements of a number of mud volcano ejecta in combination with laboratory mineral spectral measurements to extract information on the viable petroleum system properties. According to the interpretation presented here, the spectral changes provide abundance estimates of hydrocarbon, source rock and clay minerals present in the mud volcano samples. Hence this information can e.g. used to estimate mud volcano rooting depth for different mud volcanoes in Azerbaijan.

\section{RESULTS}

The application of VMESMA is demonstrated on ASD field data and ASTER imagery of Aktharma-Pashaly mud volcano with different spectral resolution.

\subsection{Mineral Abundances in Field Data}

Reflectance spectra of USGS spectral library yield input for the VMESMA analysis and mean abundance estimates for calcite, chlorite, dolomite, hematite, illite, jarosite, kaolinite, montmorillonite, and vermiculite per mud volcano are given in figure 2 . About $54.8 \%$ of the pixels are modelled using a 2-EM set, and a 3-EM model described 45.2 $\%$. Abundance histograms show that even using a relatively small number of endmembers, the model produces only $1.5 \%$ of the values as negative as -0.05 . The model estimates high illite abundance for AktharmaPashaly, Baghar, and Cheildag mud volcanoes, and high montmorillonite abundances for Bozdag and Lokbatan mud volcanoes. Previously mentioned these minerals resemble Miocene and Pliocene sediments respectively so we are able to separate various geologic sequences in terms of mineral abundance estimates. Unfortunately no laboratory measurements are available yet to confirm these results. Kaolinite mineral abundances, which mainly show secondary mineral alterations were not found in the samples. Also pyrite show high abundance estimates in the unmixing results. Due to the endmember standardisation procedure in the VMESMA algorithm, pyrite abundance estimates cannot be confused with low reflectance in general since the standardized pyrite spectrum shows a little iron absorption feature in the NIR part of the electromagnetic spectrum.

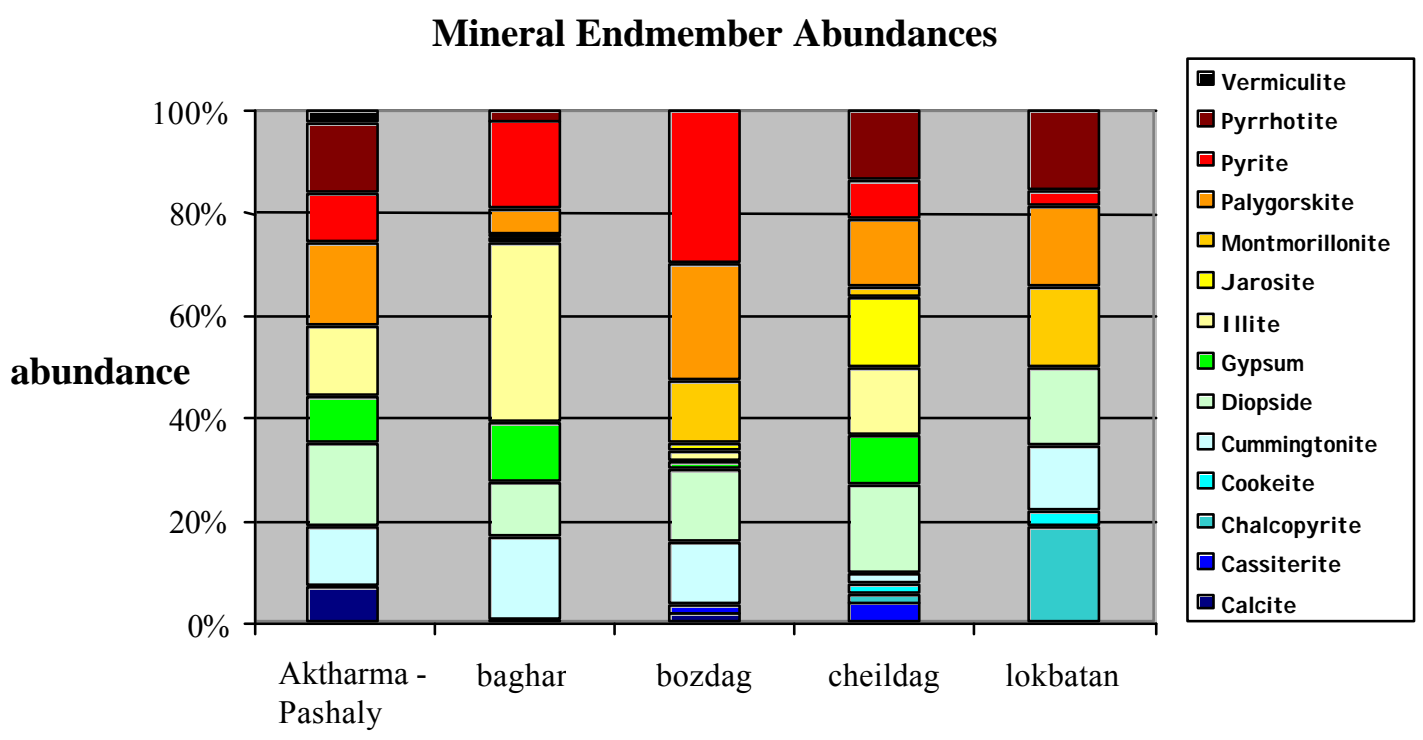

Fi gure 2. Stacked column mineral abundances of several onshore mud volcanoes in Azerbaijan. 


\subsection{Mineral Abundances in ASTER Data}

Three ASTER images from Aktharma-Pashaly mud volcano were empirical line corrected using ground truth field spectral reflectance measurements and VMESMA was applied. Four image segmentations were created in which each image segment represents an ASTER SWIR mineral assemblage. For example, segment1 incorporates all the pixels that show 2.16 absorption and probably indicate low $\mathrm{pH}$ or acid environments (table 1). We used ASTER band ratios to calculate pixels, which show typical absorption at particular wavelengths. After several attempts statistics showed that a $2 \mathrm{EM}$-model fits the dataset the best and hence gives the best results in terms of low RMSerror en only $2 \%$ of negative violations. Figure 3 maps the distribution and relative abundance of AlH bearing minerals for AktharmaPashaly in a RGB plot with respectively the AHOH kaolinite (kaolinite endmember), the Al $\mathrm{OH}$ (montmorillonite - muscovite endmembers) group and the Al-OH (illite - Al smectite endmembers) group. It is suggested that ASTER identifies classes of aluminium hydroxyl bearing minerals, the most significant being the detection of the kaolinite group (red). The kaolinite group shows a radial pattern and they mainly appear near 2 faults in the area, indicated with a yellow line in the small ASTER RGB=321 colour composite. Probably mud migration mechanisms might be confined to faults present in the area and probably highlight argillic altered environments. In the centre of the mud volcano $\mathrm{AlOH}$ group montmorillonite/muscovite shows high abundance estimates, a fair indication of the minerals from the subsurface. In the ASTER image of August 2002, high illite Al smectite bundances are estimated at the southwest mud volcano vent-group, probably an indication of fresh mud ejecta from the subsurface.

\subsection{Interferometric SAR Data (InSAR)}

Preliminary VMESMA results show that ASTER images can detect Al-OH mineral zonations as a result of active mud volcanism. In principal, in terms of spatial patterns recognition, InSAR interferometry should be able to locate deformation patterns caused by mud volcano eruptions. Using two SAR images, acquired using repeated acquisitions, it is possible to obtain relative altitude information through phase to altitude conversion using

$$
H=-\frac{\lambda R \sin \theta}{4 \pi B_{\perp}} \partial \phi
$$

in which $\lambda$ is the radar wavelength, $R$ is the range (distance from satellite to point $P$ on reference surface), $\theta$ is the satellite look angle, $\mathrm{B}_{1}$ is the perpendicular baseline and $\partial \phi$ is the phase difference [13]. The use of phase measurements (multiplicative interferometry) enabled the observation of relative distances as a fraction of the radar wavelength, and the difference in the sensor locations enabled the observation of angular differences, necessary for topographic modelling [13]. In terms of deformation monitoring, the relative line-of-sight movement of scatterers with respect to a reference location in the image could be measured as a fraction of the wavelength, yielding $\mathrm{cm}$ to $\mathrm{mm}$ accuracies. The problem that the deformation signal is always mixed with the topographic signal is solved with differential interferometry. Three ERS-2 Synthetic Aperture Radar images from Aktharma-Pashaly mud volcano are analysed and it was attempted to extract deformation information from InSAR tandem pairs with a $2-$ year timespan. However fair correlation between two different tandem pairs was only available for imagery with a limited timespan of 70 days (figure 4) and no spatial deformation was noticed. When the timespan is larger than 70 days, there appears too much noise in the data, probably due to changes in the surface cover at the mud volcano, or different atmospheric conditions in the different scenes

\section{FUTURE WORK}

We hope to obtain good correlation results in the processing of the remaining InSAR tandem pairs to assess the spatial dimensions of the apparent mud, oil, and gas seepages at Aktharma-Pashaly. In addition volume estimation through deformation values can be seen as an equivalent to mud chamber volume in the subsurface. We try to combine the apparent mudflow volumes, deformation values and mineral abundance estimations into a simple model to monitor mud volcano eruptions, based on [14].

\section{ACKNOWLEDGMENTSS}

The authors are grateful to Dr. F.J. García-Haro for usage of the VMESMA algorithm. The interferograms have been processed using the repeat orbit interferometry pack -age ROI PAC developed at Stanford University. 


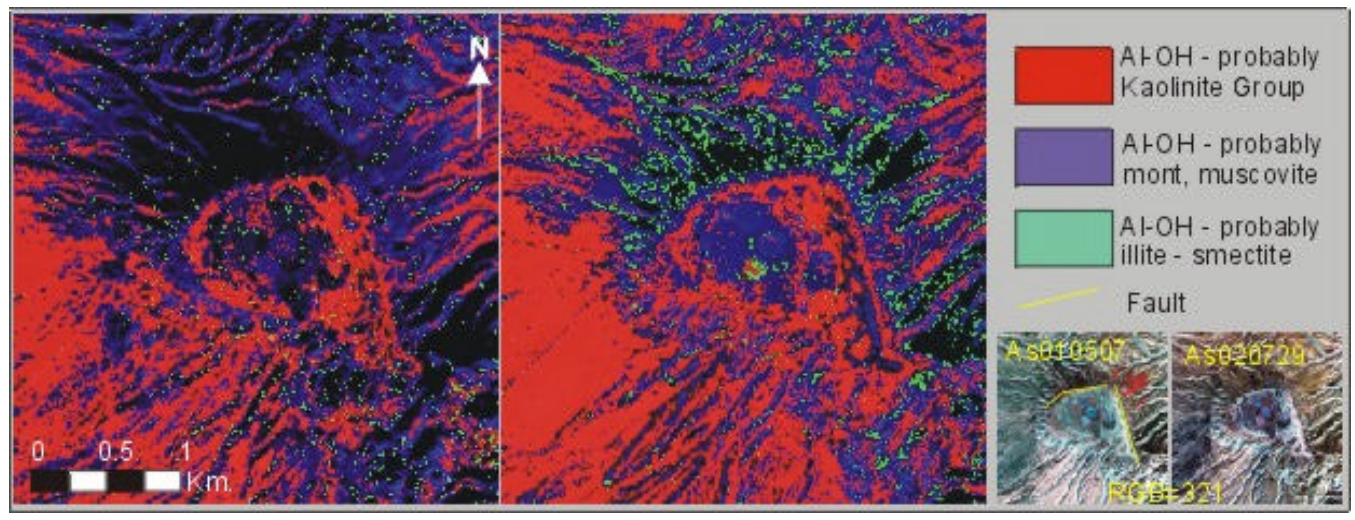

Figure 3. ASTER Al-OH mineral map of AktharmaPashaly mud volcano.
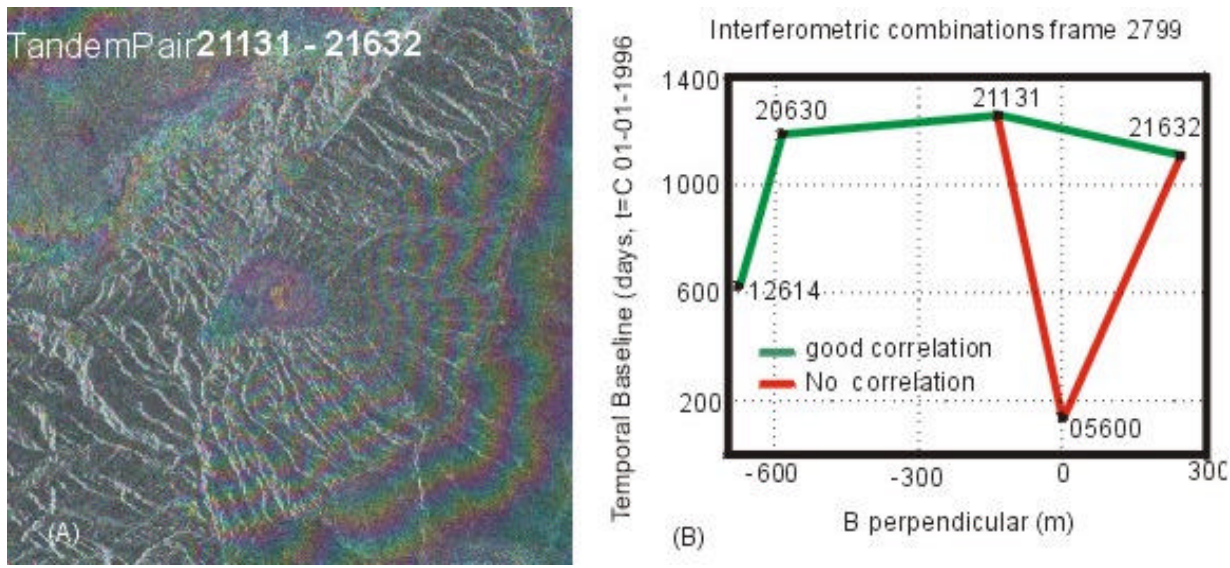

Figure 4. (a) InSAR tandem pair combination showing fringes indicating fair correlation between different SAR images for Aktharma-Pashaly and (b) Perpendicular versus Temporal baseline plot in which green lines show tandem pairs with fair correlation and red lines show little or no correlation between the imagery

\section{REFERENCES}

[1] ABRAMS, M.A., and NARIMANOV A.A., 2000: Geochemical evaluation of hydrocarbons and their potential sources in the western South Caspian depression, Republic of Azerbaijan. Marine and Petroleum Geology, 14, no.4, pp.451-468.

[2] KATZ, B., RICHARDS, D., LONG, D., and LAWRENCE, W., 2000: A new look at the components of the petroleum system of the South Caspian Basin. Journal of Petroleum Science and Engineering, 28, pp.161-182.

[3] LERCHE, I. and BAGIROV, E., 1998: Guide to gas hydrate stability in various geological settings. Marine and Petroleum Geology, 15, pp.427-437.

[4] BURYAKOVSKY, L.A., DJEVANSHIR, R.Dj. and CHILINGAR, G.V., 1995: Abnormally-high formation pressures in Azerbaijan and the South Caspian Basin (as related to smectite ? illite transformations during diagenesis and catagenesis, Journal of Petroleum Science and Engineering, 13, pp.203-218.

[5] KOPF, A.J., 2002: Significance of mud volcanism. Reviews of Geophysics, 40, no.2, pp.2-1-2-52.

[6] GULIEV, I.S. and FEIZULLAYEV, A.A., 1997: All about Mud volcanoes, Nafta-Press, Baku, 1997.

[7] INAN, S, YALÇIN, M.N., GULIEV, I.S., KULIEV, K., and FEIZULLAYEV, A.A., 1997: Deep petroleum occurrences in the lower Kura depression, South Caspian Basin, Azerbaijan: an organic geochemical and basin modelling study. Marine and Petroleum Geology, 14, no.7/8, pp.731-762. 
[8] SAUNDERS, D.F., BURSON, K.R. \& THOMPSON, C.K., 1999: Model for hydrocarbon microseepage and related near-surface alterations. AAPG Bulletin, 83(1), 170-185.

[9] SCHUMACHER, D. and ABRAMS, A. A., 1996: Hydrocarbon microseepage and its near-surface expression. AAPG Memoir 66, pp.446.

[10] HUNT, G.R., 1977: Spectral Signatures of particulate minerals in the visible and near infrared. Geophysics, vol 42, no3, p501-513.

[11] HORNIBROOK, M., 2002: Sectral unmixing of aster data, Escondida North, Chile. Poster Presentation at Geoimage PTY ltd, Spectral Geology P/L, Eltham, Victoria, Australia.

[12] GARCÍA-HARO, F. J., KEMPER, T., and SOMMER, S., 2001, Variable multiple endmember spectral mixture analysis (VMESMA): a high performance computing and environment analysis tool, Remote Sensing of Environment, ready for submission.

[13] HANSSEN, R.F., 2001: Radar interferometry: Data Interpretation and Error Analysis. Dordrecht: Kluwer Academic Publishers.

[14] LERChE, I., A.A. Ali-ZADE, I.S. GUliYEV, E. BAGIROV, R. NADIROV, M. TAGIYEV, and A. A. FEIZULLAYEV, 1997, South Caspian Basin: stratigraphy, geochemistry and risk analysis, Azerbaijan Academy of Sciences, Nafta Press, Baku, p1-50. 